\title{
Evolution of the Microstructure of the Copper Alloy (DIN-ECu-57) in the Deformation Zone in the Process of Pressing Conform
}

\author{
Alexander V. Zinoviev ${ }^{1, a}$, Alexander N. Koshmin ${ }^{1, b}$ * \\ and Alexander Y. Chasnikov ${ }^{2, c}$
}

\author{
${ }^{1} \mathrm{NUST}$ MISiS, Department of metal forming under pressure, Moscow, Russia \\ ${ }^{2}$ New Metallurgical Technologies Ltd., Kolchugino, Russia \\ azinoviev@pdss.misis.ru, ${ }^{b}$ madswom@yandex.ru, ${ }^{c}$ ac1945@yandex.ru
}

\begin{abstract}
Keywords: conform; copper alloy; evolution of the microstructure; hardness test; deformation zone.
\end{abstract}

\begin{abstract}
The process of continuous extrusion Conform, relating to modern energy-efficient metalworking technologies, is now widespread in the production of hollow and solid, long-cut profiles of various cross-sections made of aluminum and copper alloys.

This work aimed at studying the nature of the metal flow and the transformation of the microstructure and mechanical properties of the copper alloy GOST-M1 (DIN-ECu-57) in the deformation zone during the pressing of round $(\varnothing 8,24,30 \mathrm{~mm})$ and flat $(10 \times 30,10 \times 60,10 \times 80$, $10 \times 100 \mathrm{~mm}$ ) profiles. It was performed on the premises of New Metallurgical Technologies Ltd. and the department of metal forming of the NUST MISiS. In the pressing process, the templates of these profiles were selected, further samples for the experiment were made and a study of the nature of the alloy's flow in a longitudinal direction was carried out (continuous casting - deformation center - finished profile).
\end{abstract}

\section{Introduction}

With the development of the level of manufacturability of production and the conditions caused by the limitations of many resources, there is a constant increase in the requirements for efficiency of equipment and technologies. In this regard, metallurgical processes, combining several stages of production, stand out as profitable against traditional technologies. These types of technologies include the process of continuous extrusion of metal through a die, by pressing it using a working wheel, called a Conform [1]. Classical pressing technology implies a much larger number of operations leading to an increase in production costs. Figures cited in the literature show the extremely favorable production efficiency of using technology equipped with Conform equipment. Thus, production costs and energy consumption, on average, are $30 \%$ lower than with the traditional method of production of pressed products [2].

In questions relating to the metal (cathode $\mathrm{Cu}$ ) flow pattern and the formation of the microstructure and mechanical properties directly in the deformation zone of process Conform, it has not been studied sufficiently [3]. However, studies on the evolution of the microstructure and the properties of $\mathrm{Cu}-\mathrm{Mg}$ and $\mathrm{Cu}-\mathrm{Cr}$ alloys are presented in sufficient detail $[4,5]$.

At present, the practice of creating effective mini-productions, including a full cycle of manufacturing a pressed product or a semi-finished product, is common in Russia. Usually, the lines with the equipment for the Conform process are also equipped with a continuous multi-strand casting machine and finishing drawing lines, as well as cutting to length, which makes such production self-sufficient, allowing control of most production stages. The company New Metallurgical Technologies Ltd., founded in 2015, and specialising in the production of copper alloy products [6], has in its composition the following equipment: induction furnace, melt volume 4-5 tons; 10-strand continuous casting machine (Up-Cast); continuous extrusion machine Conform 350; line of hydraulic drawing and cutting (for lengths up to $10 \mathrm{~m}$ ). 


\section{Investigation of Deformation Processes during Conform Extrusion}

The Principle of Continuous Extrusion Conform. The implementation of the Conform process occurs under the action of active frictional forces. The main element of the machine is the working wheel, with the caliber (groove) covered by a thin layer of copper, to increase the coefficient of friction. As it rotates, the wheel pushes the rod workpiece into the channel formed by the wheel and shoe (Fig. 1).

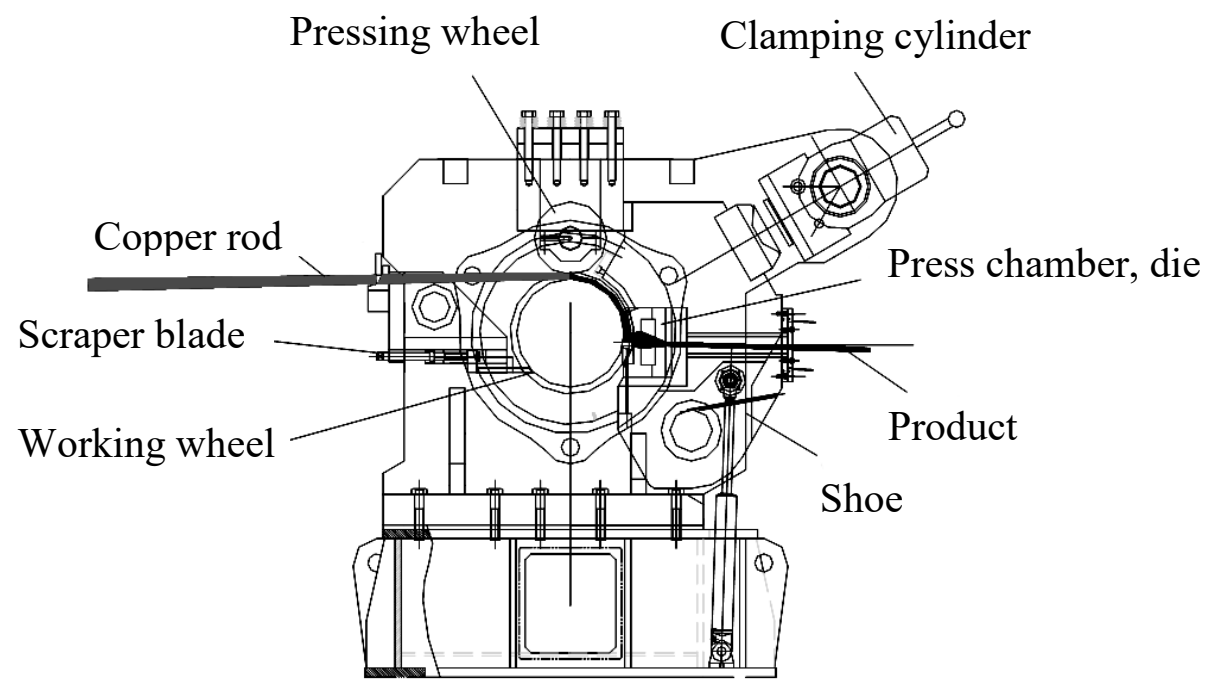

Fig. 1. The scheme of the Conform extrusion process

Next, the workpiece moves to the press chamber, where the metal changes its direction of motion to the perpendicular. Due to a large compressive force, as well as shear deformation, extensive heat release occurs. The metal temperature in the deformation zone reaches $450-500{ }^{\circ} \mathrm{C}$, which makes it possible to carry out the extrusion process without preheating the workpiece [7].

Further, the heated metal, when sufficient forces are reached, fills the press chamber and is extruded through the die, taking the shape of the final product. Directly at the exit from the matrix, the profile enters the cooling zone, a tank with a water-alcohol solution, in order to prevent oxidation of the hot surface of the product.

The Experiment preparation. Pressing profiles of copper alloys on the Conform equipment is carried out from a rod of electrotechnical copper of grade GOST-M1 (DIN-ECu-57). Cast rods with a diameter of $16 \mathrm{~mm}$ were used for all extruded profile sizes. The extrusion was carried out on a Conform 350 machine ( $350 \mathrm{~mm}$ working wheel diameter) at a temperature of $450^{\circ} \mathrm{C}$ and an extrusion speed of $75 \mathrm{rpm}$.

The structure of the cast sample of copper, along the casting direction in the central section, is characterized by the presence of large grains (Fig. 2). Individual crystallites can reach sizes of $800-$ $1000 \mu \mathrm{m}$. The different color of crystallites is due to the different yields of crystallographic planes on the surface of the probe and, naturally, different chemical activity.

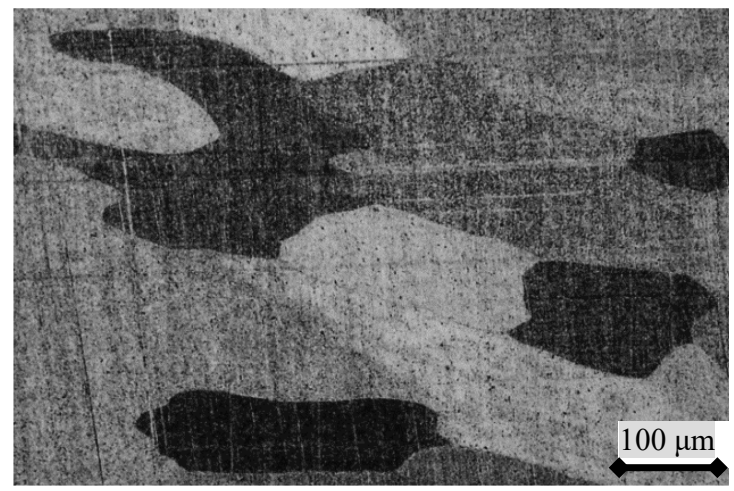

Fig. 2. Microstructure of the central section of a copper cast rod before the extrusion process 
To study the process of deformation, templates from the press remnants of rods and buses of different sizes were used (Fig. 3). The selection of templates was carried out from industrial batches, at the enterprise "NMT" Ltd., Kolchugino. They are conventionally divided into two parts: the part that is deformed and recrystallized in the press chamber, and the part which was pressed through the die, and assumed the form of the final product.

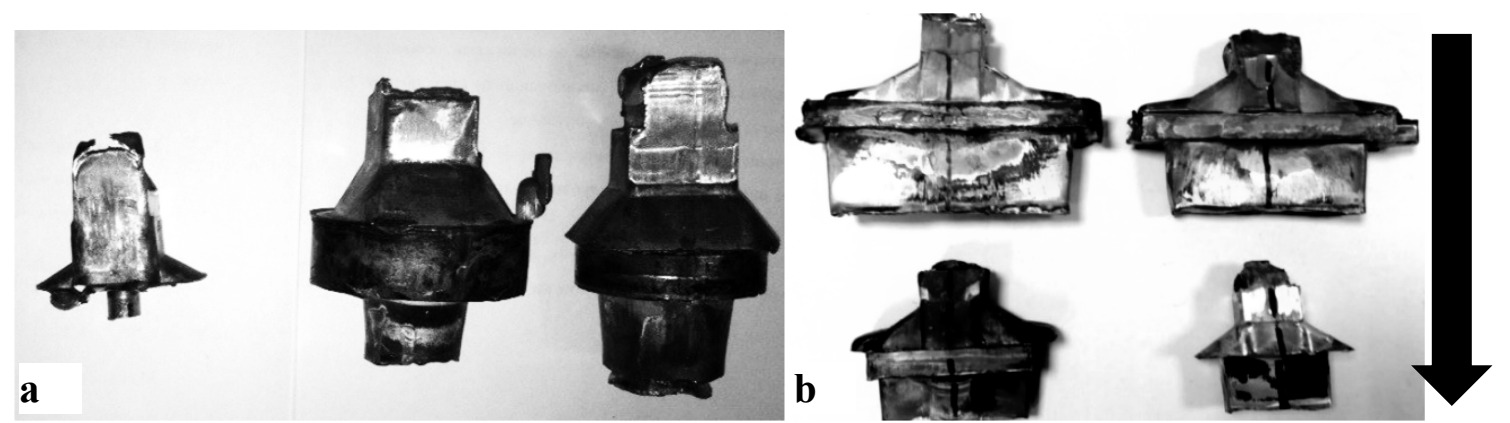

Fig. 3. Press-residues from pressing: a) rods of 8,24 and $30 \mathrm{~mm}$ in diameter; b) buses with a thickness of $10 \mathrm{~mm}$ and a width of 100, 80, 60 and $30 \mathrm{~mm}$. (Direction of extrusion indicated by an arrow)

Further, from the templates, samples were taken and polished sections were made for studying the microstructure using an optical microscope with a magnification of $x 85$. The microstructural samples were etched with an aqueous solution of a mixture of acids $\left(\mathrm{HNO}_{3}, \mathrm{HCl}, \mathrm{H}_{2} \mathrm{SO}_{4}\right)$. The microstructure was studied in two sections of samples representing the zone in the center of the deformation center, directly in the press chamber, and the zone at the exit from the die. Pictures of the structure are given in Table 1.

After studying the array of microsections on a microscope, mechanical tests were carried out on a hardness meter HVS-1000, at a load of 1000 grams, according to the Vickers method.

\section{Results and Discussion}

In accordance with the nature of the metal movement, the cast bar is fed into the pressing chamber at a speed of $4 \mathrm{~m} / \mathrm{min}$ under the action of friction forces, where the metal deforms and the cast structure breaks down, and the smaller recrystallized structure is formed with grain sizes of 35 $-40 \mu \mathrm{m}$, in the case of a $8 \mathrm{~mm}$ diameter bar, determined by comparison with the standard (Table 2 , No. 1, zone A) [6]. Further, the material enters the die with a predetermined configuration and expires therefrom. In the figure (Table 2, No. 1, zone B), the microstructure of a rod that is $8 \mathrm{~mm}$ in diameter is shown in the longitudinal section, in the zone behind the die. When considering the microstructure, one can observe the certain orientation of grains in the extrusion direction, and the similarity of the recrystallization texture.

The overall picture of the destruction of the cast's crystalline structure is also preserved in the region in front of the matrix when pressing bars with a diameter of $24 \mathrm{~mm}$ with some difference in the grain size (Table 2, No. 2, zone A). Small areas with a larger grain size, up to $50 \mu \mathrm{m}$, appear here. In zone B, some orientation of the grains along the pressing direction can be noted. A similar pattern of structure formation is retained even when pressing bars with a diameter of $30 \mathrm{~mm}$ (Table 2, No. 3). 
Table 1. Evolution of the copper alloy microstructure in the deformation center

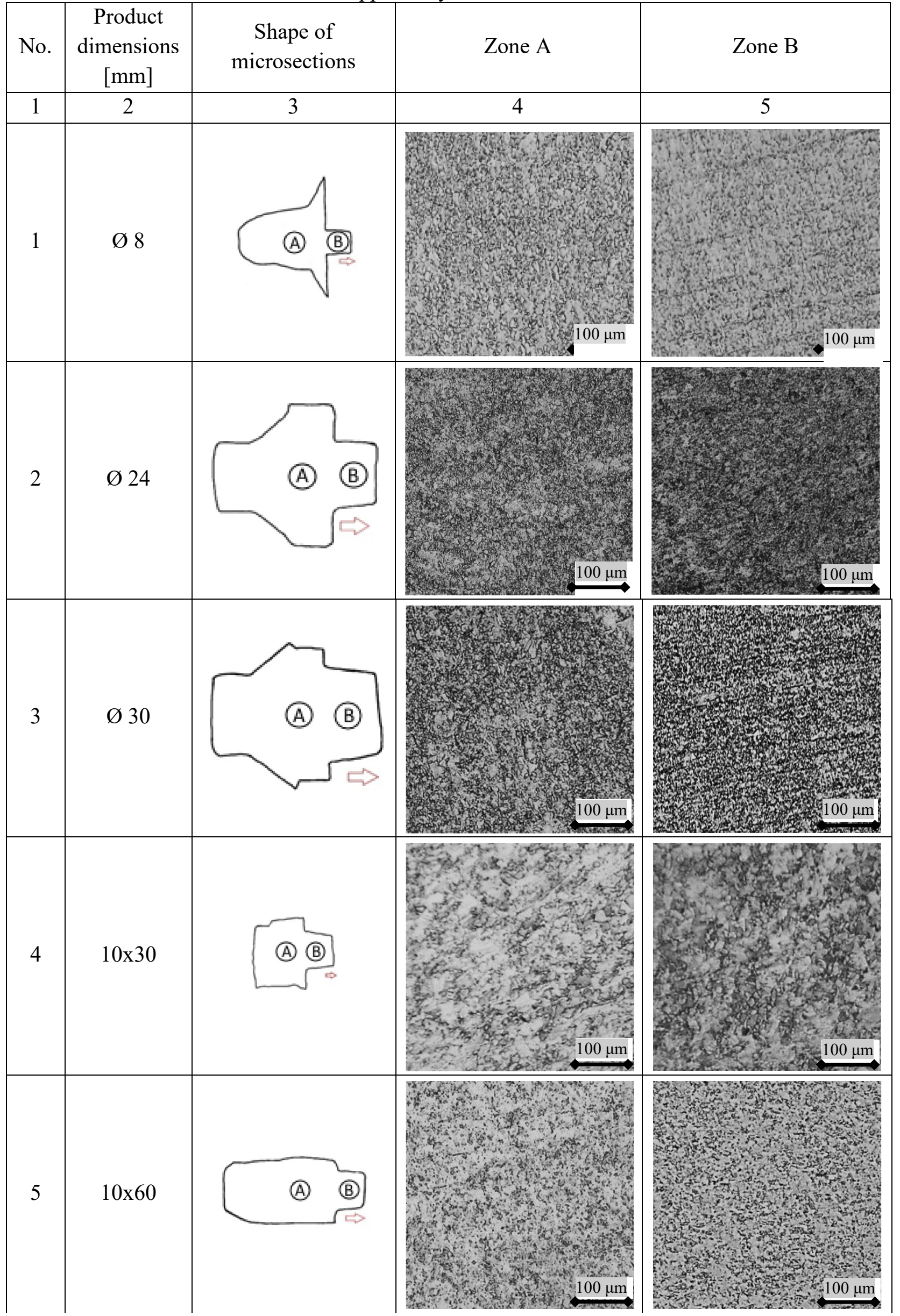


Continuation of table 1

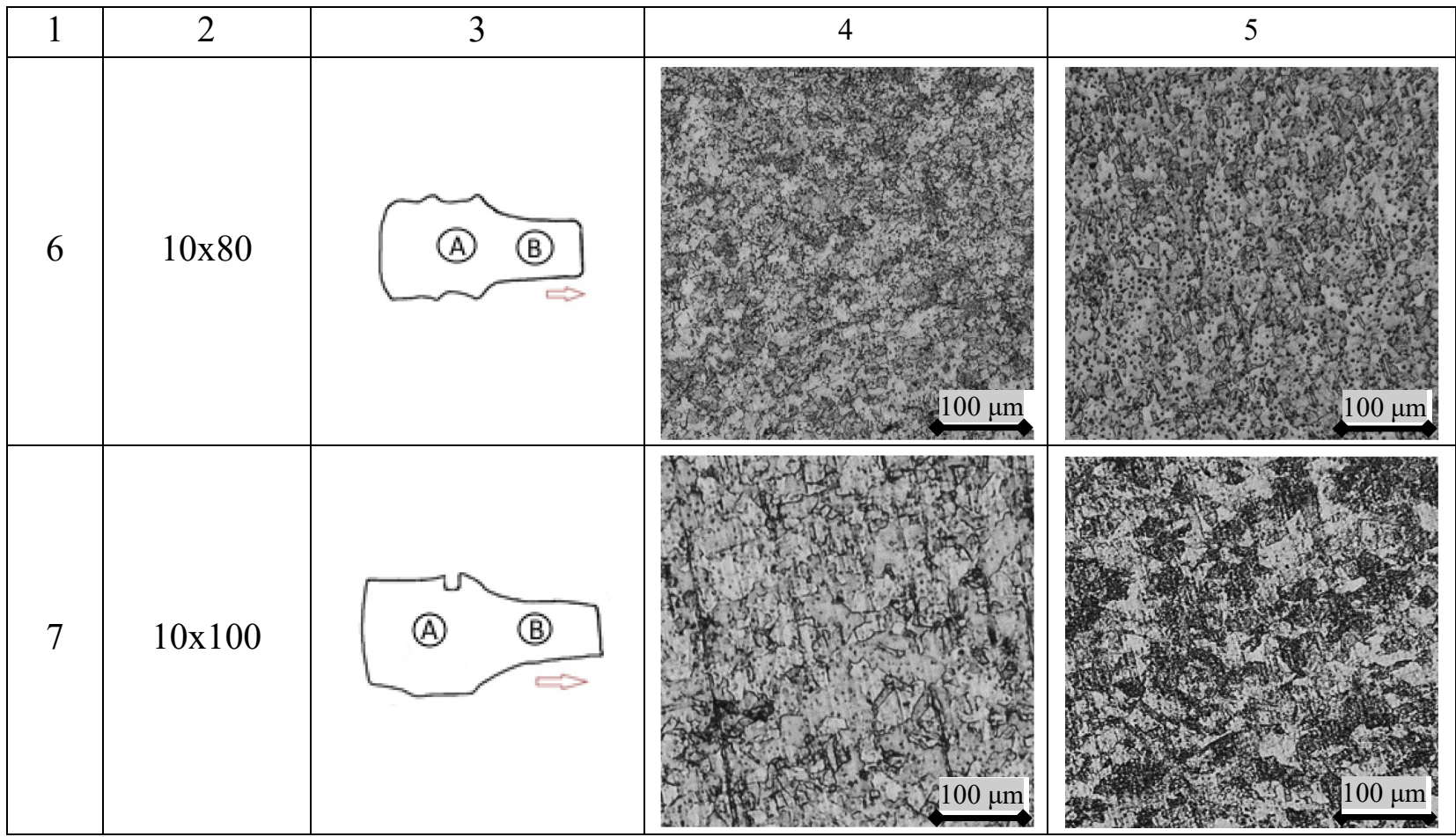

A study of the nature of the change in the microstructure of copper samples during extrusion of buses showed that the general patterns governing the formation of the structure of samples taken before and after the die are generally preserved. The microstructure of the bus probe with dimensions of $10 \times 30 \mathrm{~mm}$ in the area of the press chamber has grains somewhat larger than those taken from the rods' extrusion. Here, too, after pressing, an oriented-directed recrystallized grain is observed. It should be noted that the character of the formation of the microstructure in front of the die, after the destruction of the cast structure, does not change, in comparison with the previously considered samples, since the essence of the Conform process, and its parameters, do not change.

In the framework of the study of the mechanical characteristics of articles of M1 grade copper, a change in the microhardness along the line of the central section in the direction of pressing of rods of 8,24 , and $30 \mathrm{~mm}$ in diameter from the filling chamber up to the exit from the die is shown (Fig. 4 , a). The length of the deformation zone displays the section of the press chamber, die, and has a different length, which is explained by the configuration of the tool.

According to the standard EN 13601, hardness is a controlled property of the pressed products. Before feeding into the filling chamber, the hardness of the cast rod with a diameter of $16 \mathrm{~mm}$ is $56.8 \mathrm{kgf} / \mathrm{mm}^{2}$, which corresponds to the soft state of grade M1 copper.

For the rod of $8 \mathrm{~mm}$ in diameter in the accumulation chamber, before entering the die, the microhardness is $98 \mathrm{~kg} / \mathrm{mm}^{2}$. As a result of the very high deformation during the extrusion process and the release of exothermic heat, its hardness is reduced to $90.8 \mathrm{~kg} / \mathrm{mm}^{2}$ (Fig. 4, a, curve 1).

For a rod with a diameter of $24 \mathrm{~mm}$, similar patterns of variation of the microhardness along the pressing direction are found. Before entering the die, the hardness in the press-chamber zone rises from 78.6 to $105.3 \mathrm{~kg} / \mathrm{mm} 2$. But as a result of the thermomechanical action in the matrix, the microhardness, as in the case of a rod of $8 \mathrm{~mm}$ in diameter, is reduced to $97.4 \mathrm{~kg} / \mathrm{mm} 2$ (Fig. 4, a, curve 2). In both cases, the maximum on curves 1 and 2 corresponds to the moment of entry of the metal into the die. 

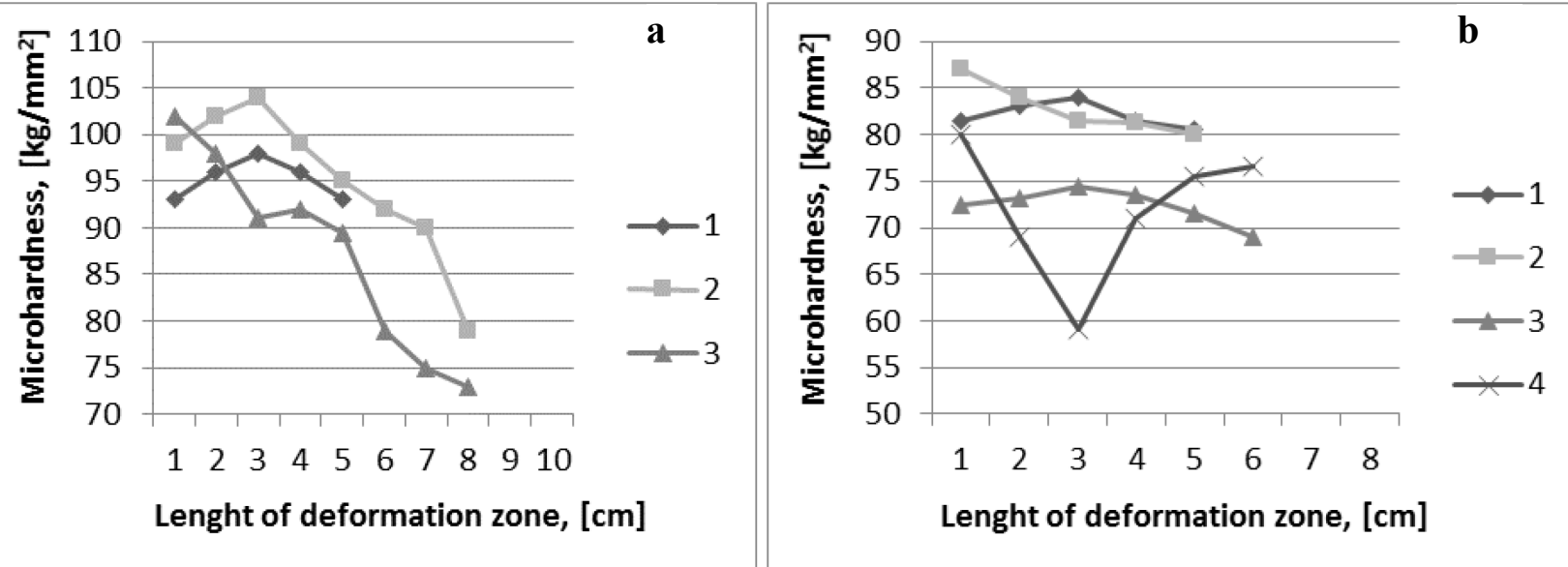

Fig. 4. Modifying of microhardness along the line of the central section: rods (a): 1-diameter $8 \mathrm{~mm}$; 2-diameter of $24 \mathrm{~mm} ; 3$ - diameter of $30 \mathrm{~mm}$; and buses (b): 1 - size $10 \times 30 \mathrm{~mm} ; 2$ - the size of $10 \times 60 \mathrm{~mm} ; 3$ - the size of $10 \times 80 \mathrm{~mm} ; 4$ - the size of $10 \times 100 \mathrm{~mm}$

In the case of pressing a rod with a diameter of $30 \mathrm{~mm}$, its maximum microhardness values are not detected on the curve, and it drops from $102 \mathrm{~kg} / \mathrm{mm}^{2}$ in the press-chamber part to $76.9 \mathrm{~kg} / \mathrm{mm}^{2}$ in the matrix as a result of the rod heating (Fig. 4, a, curve 3). Such a course of the curve is due to the much larger volume of metal in the accumulation chamber, and somewhat smaller, in comparison with the pressing of smaller diameters by volume deformations during the passage of the die.

The microhardness measurement scheme along the centerline of pressed buses with a size of $10 \times 30,10 \times 60,10 \times 80$, and $10 \times 100 \mathrm{~mm}$ is similar to the microhardness testing of pressed rods. The results of the study are shown in Figure 4, b. For buses with a size of $10 \times 30-80 \mathrm{~mm}$, a small maximum of values is found before entering the die zone and then a decrease in the microhardness values occurs when the matrix is passed through, for the above reasons, as with the rods (Fig. 4, b, curves 1-3).

With a bus measuring $10 \times 100 \mathrm{~mm}$, the patterns of microhardness change are significantly different. This is due to the considerable volume of metal in the press chamber in this case. As the metal accumulates under the conditions of the continuity of the process Conform, and its temperature is raised to $480{ }^{\circ} \mathrm{C}$, the microhardness immediately before the die falls from 81.2 to $59.1 \mathrm{~kg} / \mathrm{mm}^{2}$. After passing through the matrix, the sufficiently large surface of the bus immediately comes into contacts it with cooling water and, as a result of the action of the thermal wedge, the microhardness again increases to $77 \mathrm{~kg} / \mathrm{mm}^{2}$ (Fig. 4, b, curve 4). In this case, the process of recrystallization does not have time to develop completely.

\section{Conclusion}

Analysis of the microstructure of rod and bus samples showed that the patterns of structure formation are similar for the entire assortment concerned - the size of the grains in the matrix area and at the outlet from it is somewhat smaller than in the zone of the press chamber. Also noted is the fact of formation orientation of the grains along the direction of the pressing process in the metal after passing the die.

The results of microhardness measurements showed that, depending on the configuration of the press container, the mechanical properties of the pressed metal can vary considerably. The hardness of the cast rod before deformation was $56.8 \mathrm{~kg} / \mathrm{mm}^{2}$. Probes of $8 \mathrm{~mm}$ diameter rods and buses with dimensions of $10 \times 30$ and $10 \times 60 \mathrm{~mm}$ have approximately the same level of hardness $\left(\sim 90 \mathrm{kgf} / \mathrm{mm}^{2}\right)$ and similar patterns of distribution of hardness values across the body of the sample. Probes made from templates of rods with a diameter of 24 and $30 \mathrm{~mm}$, and the templates of buses with dimensions of $10 \times 80$ and $10 \times 100$ have values of hardness that tend to decrease during passage through the matrix, which is caused by softening processes due to high temperatures in the press chamber and a lesser deformation degree. 
Efficiency and profitability of Conform continuous extrusion technology makes this process extremely attractive in the production of various profiles of high-plastic alloys, but the constructive complexity and low level of research devoted to the peculiarities of the process slows its development. These factors open the way for further, deeper research and analysis of the specifics of the Conform process.

\section{References}

[1] D. Green, Continuous Extrusion-Forming of Wire Section, Journal of the Institute of Metals (London) 100 (1972) 295-300.

[2] Y.N. Raikov, Copper processing: A textbook for high schools. OJSC "Institute Tsvetmetobrabotka", Moscow, 2006, pp. 229-231.

[3] I.L. Konstantinov, S.B. Sidelnikov, Fundamentals of technological processes of metal forming: a textbook, SFU, Krasnoyarsk (2015).

[4] Lianpeng Song, Yuan Yuan, Zhimin Yin, Microstructural Evolution in Cu-Mg Alloy Processed by Conform, International Journal of Nonferrous Metallurgy 2 (2013) 100-105.

[5] Yuan Yuan, Zhou Li, Zhu Xiao, Ziqian Zhao, Ziqi Yang, Microstructure evolution and properties of $\mathrm{Cu}-\mathrm{Cr}$ alloy during continuous extrusion process, Journal of Alloys and Compounds 703 (2017) 454-460.

[6] A.V. Zinoviev, A.Y. Chasnikov, Physicomechanical properties and plastic deformation of copper and its alloys, IRIAS, Moscow, (2009).

[7] Y.V. Gorokhov, V.G. Sherkunov, N.N. Dovzhenko, S.V. Belyaev, I.N. Dovzhenko, Basics of designing processes for the continuous pressing of metals, Monograph, SFU, Krasnoyarsk (2013). 